\title{
Regulador de crescimento em plantas de trigo: reflexos sobre o desenvolvimento vegetativo, rendimento e qualidade de grãos
}

\author{
Geraldo Chavarria ${ }^{1 *}$, Willian Pelisser da Rosa ${ }^{2}$, Laércio Hoffmann ${ }^{3}$, Miria Rosa Durigon ${ }^{4}$ \\ http://dx.doi.org/10.1590/0034-737X201562060011
}

\begin{abstract}
RESUMO
Reguladores de crescimento podem ser utilizados com o intuito de evitar o acamamento do trigo, porém, podem apresentar outros benefícios, em função da melhoria da interceptação de luz e da realocação de carbono. O objetivo deste trabalho foi avaliar a influência do regulador de crescimento (trinexapac-etil) sobre o desenvolvimento vegetativo, os componentes da produção e a qualidade de grãos de dois cultivares de trigo distintos em relação à susceptibilidade ao acamamento. Um experimento foi realizado em casa de vegetação e outro a campo. No experimento em casa de vegetação, foram avaliadas as variáveis de desenvolvimento vegetativo (estatura de planta, relação entre raiz e parte aérea, áreas foliares unitária e total, comprimento e matéria seca de raízes) em plantas de trigo, com e sem a aplicação de trinexapac-etil, em estádio de primeiro nó visível e segundo nó perceptível. A campo foram avaliadas variáveis de desenvolvimento vegetativo (clorofila, estatura e área foliar), rendimento (número de espigas, massa de mil grãos e produtividade) e qualidade (massa do hectolitro e conteúdo de proteína), em plantas de trigo com variações de aplicação de trinexapac-etil (testemunha sem aplicação, perfilhamento e primeiro nó visível e segundo perceptível). O regulador de crescimento trinexapac-etil aumenta a relação entre raiz e parte aérea do cultivar Mirante e a produtividade dos cultivares Quartzo e Mirante. Porém, não interfere na qualidade de grãos desses cultivares.
\end{abstract}

Palavras-chave: trinexapac-etil, redutor de crescimento, Triticum aestivum L., manejo.

\section{ABSTRACT}

\section{Growth regulator in wheat: effects on vegetative development, yield and grain quality}

Growth regulators can be used to avoid wheat lodging, but can also bring benefits such as increase in intercepted radiation and carbon reallocation. The aim of this study was to evaluate the effect of a growth regulator (trinexapacethyl) on the vegetative development, production components and grain quality of two wheat cultivars with different susceptibility to lodging. Two experiments were carried out; one in a green house and another in the field. In the green house experiment, the vegetative development variables (plant height, leaf area, root: shootratio, length and dry mass of roots) were evaluated with and without application of trinexapac-ethyl on the first visible node and on the second noticeable node. The following characteristics were evaluated in the field: vegetative development, yield and quality grain variables (hectoliter mass and protein content) with varying trinexapac-ethyl applications (untreated control, tillering, first visible node and second notice able node). The growth regulator trinexapac-ethyl increased the root: shoot ratio in the cultivar Mirante and increased the yield in the cultivars Quartzo and Mirante. However, the growth regulator did not influence the grain quality of these cultivars.

Key words: trinexapac-ethyl, growth reducer, Triticum aestivum L., management.

Submetido em 02/04/2014 e aprovado em 19/08/2015

1 Universidade de Passo Fundo, Faculdade de Agronomia e Medicina Veterinária, Passo Fundo, Rio Grande do Sul, Brasil. geraldochavarria@upf.br

2 Universidade de Passo Fundo, Faculdade de Agronomia e Medicina Veterinária, Passo Fundo, Rio Grande do Sul, Brasil. wpelisser@yahoo.com.br

3 Universidade de Passo Fundo, Faculdade de Agronomia e Medicina Veterinária, Passo Fundo, Rio Grande do Sul, Brasil. laercio.hoffmann@syngenta.com

4 Universidade de Passo Fundo, Faculdade de Agronomia e Medicina Veterinária, Passo Fundo, Rio Grande do Sul, Brasil. midurigon@yahoo.com.br

*Autor para correspondência: geraldochavarria @upf.br 


\section{INTRODUÇÃO}

A cultura do trigo (Triticum aestivum L.) é de fundamental importância no sistema de produção agrícola do centro-sul e do sul do Brasil. A produção anual oscila entre cinco e seis milhões de toneladas, porém o consumo anual do país tem-se mantido em torno de dez milhões de toneladas. Os principais estados produtores do Brasil são Paraná e Rio Grande do Sul, sendo que cerca de $90 \%$ da produção de trigo está concentrada no sul do Brasil (IBGE, 2011).

Dentre os aspectos básicos de busca por produção e qualidade de grãos de trigo, o manejo adequado do nitrogênio tem grande relevância, pois o conteúdo desse elemento na planta determinará seu potencial de desenvolvimento até o final de acúmulo proteico (Gomes Júnior et al., 2005). Todavia, uma das limitações da fertilização nitrogenada é o crescimento vegetativo excessivo, que pode resultar em acamamento de plantas e reduções de produtividade e de qualidade de grãos (Peltonen, 1992; Penckowski et al., 2009).

Reguladores de crescimento são substâncias não sintetizadas pelas plantas que influenciam seu crescimento (Taiz \& Zeiger, 2004). Os resultados de regulação de crescimento de plantas apresentam-se cada vez mais promissores, na redução de estatura, na mitigação ou no estímulo de senescência de folhas, como também, no uso para maturação de frutos (Scudeler et al., 2004; Zanqueta et al., 2004; Pedersen et al., 2006).

O trinexapac-etil é um inibidor da biossíntese de giberelina, que tem por objetivo, na cultura do trigo, reduzir a estatura de plantas e, consequentemente, possibilitar maior aporte de nitrogênio (Zagonel \& Fernandes, 2007). Além desse benefício, discute-se a possibilidade de a redução do crescimento das plantas de trigo culminar em maior rendimento, pela melhor capacidade de interceptação de radiação solar, em momentos importantes de definição de produção, assim como, pelo direcionamento do carbono não usado no crescimento em estatura. Todavia, não existem trabalhos científicos que corroborem essas informações para os cultivares de trigo produzidos nas condições ambientais do Estado do Rio Grande do Sul.

O objetivo deste trabalho foi determinar a influência do regulador de crescimento trinexapac-etil sobre o desenvolvimento vegetativo, os componentes de rendimento e a qualidade de grãos de dois cultivares de trigo com comportamentos distintos de susceptibilidade ao acamamento de plantas.

\section{MATERIAL E MÉTODOS}

O trabalho foi conduzido em duas etapas, uma em condições controladas em casa de vegetação e, outra, a campo, no ano de 2012, utilizando-se os cultivares de trigo Quartzo (tolerante ao acamamento) e Mirante (susceptível ao acamamento). Os dois experimentos foram conduzidos no esquema bifatorial (regulador de crescimento e cultivar). No experimento em casa vegetação, o fator regulador de crescimento apresentou dois níveis e, no experimento a campo, três níveis.

No experimento em casa de vegetação, sementes dos dois cultivares foram semeadas em vasos de $11 \mathrm{~L}$ de volume com solo de horizonte A (Latossolo VermelhoEscuro distrófico estruturado) e substrato marca PlantMax® (v:v). A adubação de semeadura foi com N, $\mathrm{P}_{2} \mathrm{O}_{5}$ e $\mathrm{K}_{2} \mathrm{O}$, conforme interpretação da análise química de solo, de acordo com o Manual de Adubação e Calagem para os estados do Rio Grande do Sul e Santa Catarina (CQFS, 2004), e a dose calculada em relação ao volume de cada vaso $(11 \mathrm{~L})$. O delineamento experimental utilizado foi em blocos casualizados, com aplicação, ou não, de regulador de crescimento, tendo 30 repetições, sendo cada vaso com quatro plantas considerado uma repetição.

Quando as plantas apresentavam o primeiro nó de crescimento visível no colmo e o segundo perceptível, foi efetuada a aplicação de trinexapac-etil (Moddus®), na dose de $350 \mathrm{~mL} \cdot \mathrm{ha}^{-1}$, utilizando-se pulverizador com propulsão de $\mathrm{CO}_{2}$, na vazão de 150 L.ha ${ }^{-1}$. No estádio fenológico de espigamento (aparecimento de espiga), foram determinadas, nas quatro plantas de cada vaso, totalizando 120 plantas por tratamento, as seguintes variáveis: estatura de planta $(\mathrm{cm})$, área foliar unitária $\left(\mathrm{cm}^{2}\right)$, área foliar total $\left(\mathrm{cm}^{2}\right)$, comprimento de raízes $(\mathrm{cm})$, massa seca de raízes e parte aérea $(\mathrm{g})$.

Em relação ao experimento a campo, o delineamento foi em blocos casualizados, com quatro repetições. As plantas de trigo dos cultivares Quartzo e Mirante foram cultivadas em semeadura direta, com os tratos culturais executados de acordo com as indicações técnicas para as culturas do trigo e do triticale (Castro et al., 2010). A semeadura do experimento de campo foi realizada, utilizando-se 350 sementes viáveis por metro quadrado, distribuídas em linhas espaçadas de 0,17 m. Os tratamentos realizados foram: aplicação de trinexapacetil no perfilhamento $\left(350 \mathrm{~mL} \cdot \mathrm{ha}^{-1}\right)$, no primeiro nó visível e segundo perceptível (350 mL.ha-1 $)$, utilizando-se pulverizador com propulsão de $\mathrm{CO}_{2}$, na vazão de 150 L.ha-1 ${ }^{-1}$ e testemunha (sem aplicação). Para a padronização da quantidade do produto aplicada em casa de vegetação e no campo, foi utilizada a mesma velocidade de aplicação $\left(3,6 \mathrm{~km} \cdot \mathrm{h}^{-1}\right)$.

Cada parcela mediu 1,87 m (11 linhas) de largura $\mathrm{x}$ $11 \mathrm{~m}$ de comprimento, com área total de $20,57 \mathrm{~m}^{2}$ e útil de $13,2 \mathrm{~m}^{2}$ (sete linhas foram colhidas). A adubação de semeadura de $\mathrm{N}, \mathrm{P}_{2} \mathrm{O}_{5}$ e $\mathrm{K}_{2} \mathrm{O}$ efetuou-se conforme inter- 
pretação da análise de solo, de acordo com o Manual de Adubação e Calagem para os estados do Rio Grande do Sul e Santa Catarina (CQFS, 2004). Durante o desenvolvimento das plantas realizaram-se os controles de plantas daninhas, de doenças e de pragas, sempre que necessário, seguindo-se as recomendações técnicas para a cultura (Castro et al., 2010).

As variáveis avaliadas a campo foram o conteúdo de clorofila a, o de clorofila b e o de clorofila total, a estatura de planta, a área foliar unitária e a total, durante o estádio de floração, os componentes do rendimento e a produtividade, ao final do experimento.

O teor de clorofila foi estimado com clorofilômetro (Marca: Falker, Modelo: ClorofiLog) no terço médio de 50 folhas por parcela, no estádio fenológico de espigamento, e, os valores, expressos em índice ICF. Neste mesmo momento, também foram coletadas 20 plantas por parcela, determinadas a estatura e as áreas foliares unitária e total,com integrador de área foliar (Marca: LiCor, Modelo: Li 3100).

Após a colheita das parcelas, foi determinado o percentual de umidade dos grãos, o número de grãos por espiga (un.), a massa de mil grãos (g), a massa do hectolitro $\left(\mathrm{kg} \mathrm{hL}^{-1}\right)$ e foi calculada a produtividade de grãos $\left(\mathrm{kg} \mathrm{ha}^{-1}\right)$, corrigida para $13 \%$ de umidade.

A determinação do conteúdo de proteína foi realizada com espectrômetro de infravermelho proximal (NIR) (Marca: Perten, Modelo: Inframatic 9200), utilizando-se amostras de $700 \mathrm{~mL}$ de volume para cada parcela, e os valores foram expressos em percentual da matéria seca.

Os resultados em casa de vegetação e em campo foram submetidos à análise de variância e as médias dos tratamentos comparadas pelo teste de Tukey, a 5\% de probabilidade do erro.

\section{RESULTADOS E DISCUSSÃO}

No experimento em casa de vegetação, as plantas de trigo dos cultivares Quartzo e Mirante que foram tratadas com trinexapac-etil tiveram uma redução significativa do crescimento vegetativo, sem interação entre os fatores (Tabela 1). Houve redução da estatura de 16,90 e $15,78 \%$, respectivamente, para os cultivares Quartzo e Mirante, com a utilização de regulador de crescimento, na avaliação realizada em estádio de espigamento. $\mathrm{O}$ trinexapac-etil tem ação sobre os meristemas intercalares, reduzindo os níveis de giberelina ativa, pela inibição da atividade da enzima 3-ß-hidroxilase, ocasionando redução da estatura das plantas (Nakayama et al.,1990; Espíndula et al., 2011). O maior benefício da redução da estatura das plantas, além de melhorar a capacidade de interceptação de radiação, é a redução de perdas em função do acamamento (Zagonel \& Fernandes, 2007).
O fator mais importante que determina a capacidade de uma planta sustentar-se é o conteúdo de lignina da parede celular (Buchanan et al., 2000). Desta forma, quando há um maior aporte de nitrogênio às plantas, haverá uma maior taxa fotossintética e, consequentemente, maior biossíntese de proteínas (Ainsworth \& Long 2005). Para tanto, é necessária uma maior demanda de esqueletos de carbono oriundos da atividade respiratória, o que pode refletir em déficit de carbono para produção de lignina (Taiz \& Zeiger, 2004; Del Río et al., 2012). Sabe-se que, em estádios iniciais de desenvolvimento, as reservas de carbono apresentam relação negativa com o conteúdo de nitrogênio (Cuzzuol et al., 2003). Sendo assim, o excesso de nitrogênio pode promover acamamento em plantas de trigo, em função da redução da biossíntese de lignina.

As quantidades de carbono da parte aérea e do sistema radicial foram modificadas pela aplicação de trinexapac-etil, no primeiro nó visível, nos dois cultivares estudados (Tabela 1). Observou-se redução da massa seca da parte aérea, de 4,91 e 11,46\%, para os cultivares, Quartzo e Mirante, respectivamente (Tabela 1). Todavia, essa tendência de redução da parte aérea com o uso do regulador de crescimento foi inversa em relação à do desenvolvimento do sistema radicial, em que foram observados incrementos de 10 e 44\%, respectivamente, para os cultivares Quartzo e Mirante (Tabela 1).

De maneira geral, observa-se que o uso do regulador de crescimento reduz o crescimento da parte aérea e tende a intereferir no incremento do sistema radicial, como se pode observar na relação entre raiz e parte aérea, que teve seu índice aumentado no cultivar Mirante (Tabela 1). Isto se deve, possivelmente, a uma maior disponibilidade de carbono, oriunda da redução de crescimento da parte aérea, que pode ser drenado para o sistema radicial. Zagonel \& Fernandes (2007) observaram que, dependendo do momento da aplicação do trinexapacetil, os cultivares de trigo respondem de forma diferenciada, apresentando, na maioria das situações, uma redução da estatura de plantas de acordo com o incremento das doses.

Em função da aplicação de regulador de crescimento, as plantas do cultivar Quartzo, em casa de vegetação, apresentaram redução de 16,54\% $\left(11,55 \mathrm{~cm}^{2}\right)$ da área foliar total, como consequência da redução de 9,66\% da área foliar unitária (Tabela 1). Também foi observada, nesse mesmo cultivar, redução do número de folhas em um percentual de $8,57 \%$.

Em relação ao experimento a campo, também não houve interação entre os fatores regulador de crescimento e cultivar. Todavia, foi observado incremento significativo dos conteúdos de clorofila a, clorofila $b$ e total das plantas do cultivar Mirante, tratadas com regula- 
dor de crescimento no primeiro nó visível, comparados com os da testemunha (Tabela 2). Porém, para as variáveis estatura e área foliar a campo, não foram observadas diferenças significativas (Tabela 2).

Fioreze \& Rodrigues (2012) observaram que a aplicação de trinexapac-etil no início da fase de alongamento resultou em reduções do comprimento e do teor de clorofila da folha bandeira de plantas de trigo. Os mesmos autores destacaram que, em função da redução da área foliar, as plantas permanceram mais eretas, o que, segundo os autores, pode favorecer a interceptação de radiação solar. Ainda, tanto em casa de vegetação quanto a campo, as plantas de trigo dos dois cultivares apresentaram a mesma característica de folha mais ereta, comparadas com as dos demais tratamentos. Esta característica favorece a interceptação de radiação solar e resulta em maior atividade fotossintética (Larcher, 2000).

De acordo com as avaliações de componentes do rendimento a campo, não foram observadas diferenças significativas em relação ao número de grãos por espiga

Tabela 1: Crescimento vegetativo de plantas de trigo dos cultivares Quartzo e Mirante, no estádio fenológico de espigamento, submetidos à aplicação de regulador de crescimento trinexapac-etil no primeiro nó de crescimento visível no colmo e segundo perceptível em casa de vegetação

\begin{tabular}{|c|c|c|c|}
\hline \multirow{2}{*}{ Variáveis de crescimento } & \multicolumn{2}{|c|}{ Cultivar Quartzo } & \multirow{2}{*}{$\mathrm{CV}(\%)$} \\
\hline & Com & Sem & \\
\hline Estatura $(\mathrm{cm})$ & $60,75 b^{*}$ & $73,10 \mathrm{a}$ & 7,25 \\
\hline Massa seca aérea (mg) & $945,48 b$ & $994,20 \mathrm{a}$ & 17,66 \\
\hline Massa seca raiz (mg) & $193,49 a$ & $154,81 \mathrm{~b}$ & 57,47 \\
\hline Comp. raiz (cm) & $13,78 \mathrm{a}$ & $12,07 \mathrm{~b}$ & 30,68 \\
\hline Relação raiz/aérea & $0,20 \mathrm{~ns}$ & $0,16 \mathrm{~ns}$ & 42,57 \\
\hline Área foliar unitária $\left(\mathrm{cm}^{2}\right)$ & $16,00 \mathrm{~b}$ & $17,71 \mathrm{a}$ & 16,10 \\
\hline Área foliar total $\left(\mathrm{cm}^{2}\right)$ & $58,27 \mathrm{~b}$ & $69,82 \mathrm{a}$ & 17,99 \\
\hline Número de folhas (un.) & $3,63 b$ & $3,97 \mathrm{a}$ & 10,18 \\
\hline \multirow{2}{*}{ Variáveis de crescimento } & \multicolumn{2}{|c|}{ Cultivar Mirante } & \multirow{2}{*}{$\operatorname{CV}(\%)$} \\
\hline & Com & Sem & \\
\hline Estatura $(\mathrm{cm})$ & $67,63 b$ & $80,30 \mathrm{a}$ & 11,43 \\
\hline Massa seca aérea (mg) & $1093,68 b$ & $1235,17 \mathrm{a}$ & 23,27 \\
\hline Massa seca raiz (mg) & $298,53 \mathrm{a}$ & $167,08 b$ & 37,12 \\
\hline Comp. raiz $(\mathrm{cm})$ & $20,87 \mathrm{a}$ & $11,50 \mathrm{~b}$ & 21,83 \\
\hline Relação raiz/aérea & $0,27 \mathrm{a}$ & $0,14 \mathrm{~b}$ & 58,73 \\
\hline Área foliar unitária $\left(\mathrm{cm}^{2}\right)$ & $14,84 \mathrm{~ns}$ & $16,12 \mathrm{~ns}$ & 17,14 \\
\hline Área foliar total $\left(\mathrm{cm}^{2}\right)$ & $58,48 \mathrm{~ns}$ & $59,95 \mathrm{~ns}$ & 17,06 \\
\hline Número de folhas (un.) & $3,93 \mathrm{~ns}$ & $3,73 \mathrm{~ns}$ & 12,29 \\
\hline
\end{tabular}

*Médias seguidas pela mesma letra minúscula na linha não diferem entre si de acordo com o teste de Tukey a 5\% de probabilidade. ns - não significativo.

Tabela 2: Estimativas do conteúdo de clorofila e do crescimento vegetativo de plantas de trigo, dos cultivares Quartzo e Mirante, no estádio fenológico de floração, submetidos à aplicação de regulador de crescimento trinexapac-etil a campo

\begin{tabular}{|c|c|c|c|c|c|}
\hline \multirow{2}{*}{ Tratamento } & \multicolumn{5}{|c|}{ Cultivar Quartzo } \\
\hline & Clorofila a & Clorofila b & Clorofila total & Estatura (cm) & Área foliar $\left(\mathrm{cm}^{2}\right)$ \\
\hline Testemunha & $30,60 \mathrm{~ns} * * *$ & $11,01 \mathrm{~ns}$ & $41,61 \mathrm{~ns}$ & $87,70 \mathrm{~ns}$ & $42,95 \mathrm{~ns}$ \\
\hline Perfilhamento & 31,31 & 11,96 & 43,27 & 89,50 & 41,35 \\
\hline $1^{\circ}$ nó visível & 31,74 & 12,34 & 44,08 & 86,65 & 42,18 \\
\hline $\mathrm{CV}(\%)$ & 4,43 & 5,44 & 4,55 & 6,22 & 18,02 \\
\hline \multirow{2}{*}{ Tratamento } & \multicolumn{5}{|c|}{ Cultivar Mirante } \\
\hline & Clorofila a & Clorofila b & Clorofila total & Estatura (cm) & Área foliar $\left(\mathrm{cm}^{2}\right)$ \\
\hline Testemunha & $35,68 b$ & $14,38 b$ & $50,07 \mathrm{~b}$ & $94,15 \mathrm{~ns}$ & $33,96 \mathrm{~ns}$ \\
\hline Perfilhamento & $36,62 \mathrm{ab}$ & $15,13 \mathrm{ab}$ & $51,76 a b$ & 87,65 & 29,55 \\
\hline $1^{\circ}$ nó visível & $36,86 \mathrm{a}$ & $15,63 \mathrm{a}$ & $52,46 a$ & 85,80 & 30,30 \\
\hline $\mathrm{CV}(\%)$ & 1,25 & 2,58 & 1,57 & 5,45 & 8,32 \\
\hline
\end{tabular}


e na massa de mil grãos (Tabela 3). Porém, foram observadas diferenças significativas quanto à produtividade, havendo incremento nos tratamentos com trinexapacetil, tanto no cultivar Quartzo quanto no Mirante (Tabela 3). Os resultados mais significativos em incremento de produção foram obtidos quando foi efetuada a aplicação do redutor de crescimento no primeiro nó visível, apresentando-se, em média, incrementos de 12,24 e de $11,08 \%$, para os cultivares Quartzo e Mirante, respectivamente (Tabela 3). Embora se possam atribuir os maiores rendimentos à redução de perdas e também pela melhor capacidade fotossintética, sugere-se um efeito do regulador de crescimento trinexapac-etil sobre a redução da atividade respiratória mitocondrial, que pode re- sultar em menor gasto de carbono pela menor taxa respiratória de manutenção (Heckman et al., 2002; Taiz \& Zeiger, 2004).

A massa do hectolitro e o conteúdo de proteínas não apresentaram variações significativas em função da utilização do regulador de crescimento trinexapac-etil (Tabela 3). O conteúdo proteico do grão, principal indicador de qualidade de grãos, geralmente apresenta variação entre 9 a $15 \%$ da matéria seca (Lasztity, 2003). Assim como o observado neste trabalho, Penckowski et al. (2010) relataram que a utilização de redutor de crescimento (trinexapac-etil), apesar de ter diminuído a estatura de planta e incrementado a produção, não afetou de forma substancial a qualidade de grãos e a da farinha obtida.

Tabela 3: Componentes do rendimento, produtividade e qualidade de trigo dos cultivares Quartzo e Mirante, submetidos à aplicação de regulador de crescimento trinexapac-etil a campo

\begin{tabular}{|c|c|c|c|c|c|}
\hline \multirow[b]{2}{*}{ Tratamento } & \multicolumn{5}{|c|}{ Cultivar Quartzo } \\
\hline & $\begin{array}{l}\text { Núm. grãos } \\
\text { espigas (un.) }\end{array}$ & $\begin{array}{c}\text { Massa de } \\
\text { mil grãos (g) }\end{array}$ & $\begin{array}{c}\text { Produtividade } \\
\left(\text { kg.ha }^{-1}\right)\end{array}$ & $\begin{array}{c}\text { Massa do hectolitro } \\
\left({\left.\mathrm{kg} .100 \mathrm{~L}^{-1}\right)}\right.\end{array}$ & $\begin{array}{c}\text { Conteúdo } \\
\text { de proteína }(\%)\end{array}$ \\
\hline Testemunha & $35,95 \mathrm{~ns}^{*}$ & $35,77 \mathrm{~ns}$ & $2744,30 \mathrm{~b}$ & $74,38 \mathrm{~ns}$ & $14,30 \mathrm{~ns}$ \\
\hline Perfilhamento & 39,75 & 34,52 & $3130,65 a$ & 74,49 & 13,70 \\
\hline $1^{\circ}$ nó visível & 36,78 & 34,69 & $3086,06 a$ & 73,93 & 14,10 \\
\hline \multirow[t]{2}{*}{$\mathrm{CV}(\%)$} & 10,93 & 2,70 & 7,12 & 1,33 & 4,60 \\
\hline & \multicolumn{5}{|c|}{ Cultivar Mirante } \\
\hline Tratamento & $\begin{array}{l}\text { Núm. grãos } \\
\text { espigas (un.) }\end{array}$ & $\begin{array}{c}\text { Massa de } \\
\text { mil grãos (g) }\end{array}$ & $\begin{array}{c}\text { Produtividade } \\
\left(\text { kg.ha }^{-1}\right)\end{array}$ & 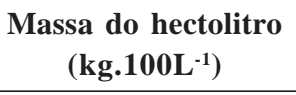 & $\begin{array}{c}\text { Conteúdo } \\
\text { de proteína }(\%)\end{array}$ \\
\hline Testemunha & $34,49 \mathrm{~ns}$ & $37,16 \mathrm{~ns}$ & $2805,79 b$ & $73,48 \mathrm{~ns}$ & $14,40 \mathrm{~ns}$ \\
\hline Perfilhamento & 33,15 & 36,66 & $2998,64 a b$ & 73,58 & 14,60 \\
\hline $1^{\circ}$ nó visível & 33,98 & 36,85 & $3196,88 \mathrm{a}$ & 74,38 & 14,30 \\
\hline $\mathrm{CV}(\%)$ & 4,45 & 4,61 & 8,44 & 0,72 & 1,62 \\
\hline
\end{tabular}

*Médias seguidas pela mesma letra minúscula na coluna não diferem entre si de acordo com o teste de Tukey a 5\% de probabilidade. ns - não significativo.

\section{CONCLUSÃO}

O regulador de crescimento trinexapac-etil aumenta o teor de clorofila e a relação entre raiz e parte aérea do cultivar Mirante e a produtividade dos cultivares de trigo Quartzo e Mirante. Porém, não interfere na qualidade de grãos desses cultivares.

\section{REFERÊNCIAS}

Ainsworth EA \& Long SP (2005) What have we learned from 15 years of free-air $\mathrm{CO}_{2}$ enrichment (FACE)? A meta-analytic review of the responses of photosynthesis, canopy properties and plant production to rising $\mathrm{CO}_{2}$. New Phytologist, 165:351-372.

Buchanan BB, Gruissem W \& Jones RL (2000) Biochemistry and molecular biology of plants. Rockville, American Society of Plant Physiologists. 1367p.

Castro RL de, Pires JLF, Pasinato A, Abichequer AD, Radin B, Lisboa B, Lau D, Paganella F, Nunes JRG, Vargas LK, Bertoldo NG, Lancini SP (2010) Informações técnicas para trigo e triticale - safra 2010. Porto Alegre, Comissão Brasileira de Pesquisa de trigo e triticale. 170p.
CQFS - Comissão de Química e Fertilidade do Solo - RS/SC (2004) Manual de adubação e calagem para os Estados do Rio Grande do Sul e Santa Catarina. 10 a ed. Porto Alegre, Sociedade Brasileira de Ciência do Solo - Núcleo Regional Sul. 400p.

Cuzzuol GRF, Carvalho MAM, Barbedo CJ \& Zaidan LBP (2003) Crescimento e conteúdo de frutanos em plantas de Vernonia herbacea (Vell.) Rusby submetidas à adubação nitrogenada. Brazilian Journal of Botany, 26:81-91.

Del Río JC, Rencoret J, Prinsen P, Martínez AT, Ralph J \& Gutierrez A (2012) Structural characterization of wheat straw lignin as revealed by analytical pyrolysis, 2D-NMR, and reductive cleavage methods. Journal of Agricultural and Food Chemistry, 60:5922-5935.

Espíndula MC, Rocha VS, Souza LT de, Souza MA de, Campanharo M \& Grossi JAS (2011) Rates of nitrogen and growth retardant trinexapac-ethyl on wheat. Ciência Rural, 41:2045-2052.

Fioreze SL \& Rodrigues JD (2012) Efeito da densidade de semeadura e de reguladores vegetais sobre os caracteres morfofisiológicos da folha bandeira do trigo. Revista Brasileira de Ciências Agrárias, 7:89-96.

Gomes Júnior FG, Lima ER, Leal AJF, Matos FA, Sá ME de \& Haga KI (2005) Teor de proteína em grãos de feijão em diferentes épocas e doses de cobertura nitrogenada. Acta Scientiarum Agronomy, 27:455-459. 
Heckman NL, Elthon TE, Horst GL \& Gaussoin RE (2002) Influence of trinexapac-ethyl on respiration of isolated wheat mitochondria. Crop Science, 42:423-427.

IBGE - Instituto Brasileiro de Geografia e Estatística [Economia] (2011) Disponível em: <http://www.ibge.gov.br/home/estatistica/indicadores/agropecuaria/lspa/lspa_201109comentarios.pdf >. Acessado em: 24 de março de 2011.

Larcher W (2000) Ecofisiologia vegetal. São Carlos, Rima. 531p.

Lasztity R (2003) Prediction of wheat quality - Success and doubts. Periodica Polytechnica Chemistry Engineering, 46:39-49.

Nakayama I, Kamiya Y, Kobayashi M, Abe H \& Sakurai A (1990) Effects of a plant-growth regulator, prohexadione, on the biosynthesis of gibberellins in cell-free systems derived from immature seeds. Plant Cell Physiology, 31:1183-1190.

Pedersen MK, Burton JD \& Coble HD (2006) Effect of cyclanilide, ethephon, auxin transport inhibitors, and temperature on whole plant defoliation. Crop Science, 46:1666-1672.

Peltonen J (1992) Ear developmental stage used for timing supplemental nitrogen application to spring wheat. Crop Science, 32:1029-1033.
Penckowski LH, Zagonel J \& Fernandes EC (2009) Nitrogênio e redutor de crescimento em trigo de alta produtividade. Acta Scientiarum Agronomy, 31:473-479.

Penckowski LH, Zagonel J \& Fernandes EC (2010) Qualidade industrial do trigo em função do trinexapac-etil e doses de nitrogênio. Ciência e Agrotecnologia, 34:1492-1499.

Scudeler F, Raetano CG, Araujo D \& Bauer FC (2004) Cobertura da pulverização e maturação de frutos do cafeeiro com ethephon em diferentes condições operacionais. Bragantia, 63:129-139.

Taiz L \& Zeiger E (2004) Fisiologia Vegetal. $3^{\mathrm{a}}$ ed. Porto Alegre, Artmed. 719 p.

Zagonel J \& Fernandes EC (2007) Doses e épocas de aplicação de redutor de crescimento afetando cultivares de trigo em duas doses de nitrogênio. Planta Daninha, 25:331-339.

Zanqueta R, Furlani Junior E, Pantano, AC \& Souza RAR de (2004) Modos de aplicação de regulador de crescimento com diferentes densidades de plantas em cultivares de algodão herbáceo (Gossypium hirsutum L. var. latifolium Hutch.). Acta Scientiarum Agronomy, 26:97105 